\title{
28. A MULTIFACTOR RISK ANALYSIS OF THE RECORD 2016 GREAT BARRIER REEF BLEACHING
}

\author{
Sophie C. Lewis and Jennie Mallela
}

\begin{abstract}
Anthropogenic greenhouse gases likely increased the risk of the extreme Great Barrier Reef bleaching event through anomalously high sea surface temperature and the accumulation of thermal stress.
\end{abstract}

Introduction. The 2016 global coral bleaching event was severe: $93 \%$ of the northern, $700 \mathrm{~km}$ stretch, of the Australian Great Barrier Reef (GBR) coral was bleached and by June, $>60 \%$ of this coral was killed in association with heat stress (Hughes et al. 2017; Fig. ES28.1). Bleaching occurred during an extended period of unprecedented global-average heat (Mann et al. 2016). Coral heat stress is accumulated through the magnitude and duration of temperatures above a threshold. A short-duration, high-magnitude event, or a long-duration low-magnitude event can cause bleaching, which is also moderated by thermal stress in preceding seasons (Ainsworth et al. 2016).

While heat stress impacts bleaching risk, coral reef health and resilience also integrates multiple environmental and biotic factors. Resilience is predetermined in part by ecosystem health that depends on historical disturbance events, the present day water

\begin{abstract}
TABLE 28.I. Qualitative assessment of climatic and environmental factors contributing to the GBR bleaching events, with letters denoting primary $(P)$ and secondary (S) influences that potentially made bleaching more likely to occur, and factors that potentially made bleaching less likely (L). Although influences are interrelated (for example, water quality is impacted by local rainfall, human activities, and the resulting runoff), they are broadly categorised as 'anthropogenic,' 'multiple,' or 'natural.'
\end{abstract}

\begin{tabular}{|c|c|c|c|c|}
\hline \multirow{2}{*}{ Category } & \multirow{2}{*}{ Factor } & \multicolumn{3}{|c|}{ Risk of Bleaching } \\
\hline & & 2016 & 2011 & 1998 \\
\hline Anthropogenic & $\begin{array}{l}\text { Climate forcings } \\
\text { (greenhouse gases) }\end{array}$ & $P$ & $S$ & S \\
\hline \multirow{2}{*}{ Multiple } & Local water quality & L & $P$ & - \\
\hline & Local climate variability & $S$ & $P$ & - \\
\hline Natural & ENSO conditions & $S$ & $S$ & $P$ \\
\hline
\end{tabular}

AFFILIATIONS: LEWIS-Fenner School of Environment and Society, Australian National University; MallelA-Research School of Biology and Research School of Earth Sciences, The Australian National University Canberra, Australian Capital Territory, Australia

DOI:10.1175/BAMS-D-17-0074.I

A supplement to this article is available online (10.1175 /BAMS-D-17-0074.2) quality (e.g., exposure to runoff) and the functional redundancy of the resident reef biota (Bellwood et al. 2003). These factors are also affected by anthropogenic activities (e.g., greenhouse gas emissions, overfishing, pollution), local weather, and large-scale modes of variability (ENSO). The 2016 ENSO episode was among the most severe recorded and may have impacted GBR bleaching.

The integration of multiple interrelated factors by reef ecosystems represents important considerations for attribution of bleaching. This study explores these complexities through a multifactor analysis of climatic and environmental influences contributing to the 2016 GBR bleaching.

Approach. Model and observational datasets were analyzed for ecosystem-relevant climatic and environmental variables (see online supplement). We investigate the influence of anthropogenic greenhouse gases (GHGs) and ENSO conditions on anomalously warm SSTs in the wider Coral Sea region that encompasses the GBR. Although the GBR occupies just a fraction of the Coral Sea region, its seasonal temperatures are highly correlated (Weller et al. 2008). We use CMIP5 climate model data (Taylor et al. 2012; Table ES28.1) to examine bleaching from a climate perspective. We use observational data from HadCRUT4 gridded (Morice et al. 2012) and NOAA OISSTV2 observed sea surface temperatures (SSTs; Reynolds et al. 2002) datasets. We explore a suite of climatic metrics (Fig. 28.1), motivated by the bleaching observed through early 2016 aerial surveys (Cressey 2016; Normile 2016), and 
(a)
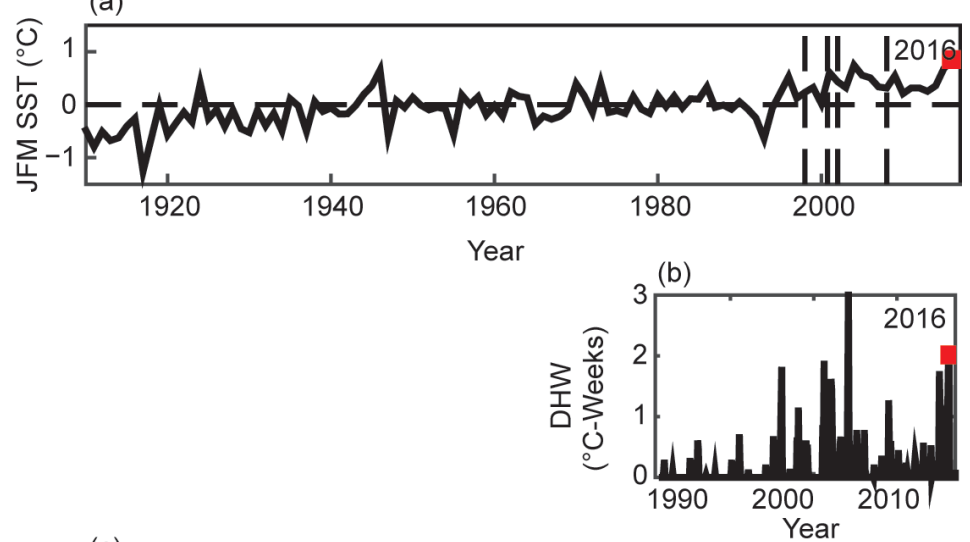

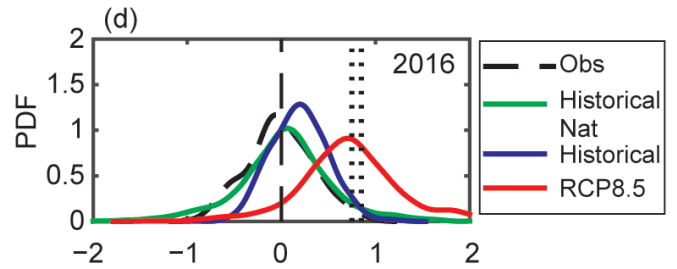

(e) JFM SST $\left({ }^{\circ} \mathrm{C}\right)$

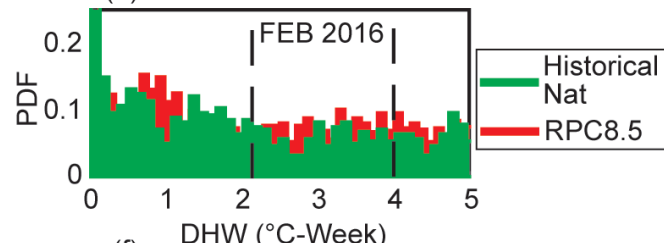

(f) $\mathrm{DHW}\left({ }^{\circ} \mathrm{C}-\right.$ Week)

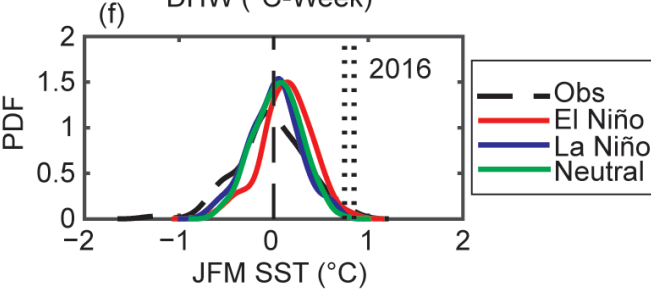

Fig. 28.I. (a) Observed Coral Sea JFM SST anomalies ( ${ }^{\circ} \mathrm{C}$; relative to $\left.196 \mathrm{I}-90\right)$, (b) DHW ( ${ }^{\circ} \mathrm{C}$-week) with hottest month calculated over 198I-2016, and (c) NIÑO3.4 JFM SST anomalies ( ${ }^{\circ} \mathrm{C}$; relative to $196 \mathrm{I}-90$ ). Probability density functions for (d) Coral Sea region JFM SST anomalies $\left({ }^{\circ} \mathrm{C}\right.$; relative to 196I-90) for observations (dashed black, 1910-2016), historical (blue, 1976-2005 only), historicalNat (green, all years), and RCP8.5 (red, 2006-20) simulations. Vertical lines show bleaching events. (e) DHW $\left({ }^{\circ} \mathrm{C}\right.$-week) is compared for historicalNat (green) and RCP8.5 (red), with $4^{\circ} \mathrm{C}$-weeks threshold. (f) PDFs show comparison of Coral Sea JFM SST anomalies $\left({ }^{\circ} \mathrm{C}\right.$; relative to I96I-90) in EI Niño (red), La Niña (green), and neutral (blue) years in the historicalNat experiment.

the record high Coral Sea SSTs (region shown in Fig. 28.2a; Bureau of Meteorology 2016) and significant El Niño conditions observed in 2016.

Analysis of a broad suite of reef-relevant climate metrics allows deeper investigation of the climatic drivers of coral thermal stress. Ainsworth et al. (2016) recently demonstrated that background warming promotes thermal tolerance in reef-building corals and potentially mitigates bleaching events.. As such, a suite of climatic metrics is required. Metrics are:

Metric 1. (Immediate heat stress): Assessed by JFM SSTs in the Coral Sea (Fig. 28.1a). Although both maximum and minimum SSTs are relevant to reef ecosystems, only mean SSTs are provided in CMIP5 (ts variable).

Metric 2. (Antecedent and coincident heat stress): Assessed by the combination of MAM and antecedent (December-February, DJF) SSTs in the Coral Sea (Fig. ES28.2a; Glynn and D'croz 1990).

Metric 3. (Cumulative stress): Assessed by anomalously high extended Coral Sea SSTs diagnosed by degree heating week (DHW; Liu et al. 2003) in each month (Fig. 28.1b).

Metric 4. (Regional conditions): Assessed by SSTs in the Niño-3.4 region in JFM (Fig. 28.1c).
We further explore bleaching by examining local environmental data. Local stressors, such as degraded water quality, potentially reduce coral resilience to episodic thermal stress and drive bleaching occurrence (Mallela et al. 2016; Carilli et al. 2009; Wooldridge 2016a). By necessity, this study does not explicitly consider all climate and environmental factors that influence coral reef health, including the impact of tropical cyclone frequency and intensity, and natural shelf-edge upwelling. Data used are:

Metric 5. Precipitation anomalies (Fig. 28.2a), which are linked to cloud cover, temperatures and run off.

Metric 6. Cloudiness anomalies (Fig. 28.2b), as increased cloud cover potentially reduces UV exposure and ameliorates thermal stress.

Metric 7. Chlorophyll-a concentrations (Fig. 28.2c), which provide an estimate of the live phytoplankton biomass in the surface layer as a nutrient indictor.

Metric 8. Concentration of particulate organic carbon (Fig. 28.2d), as an indicator of water quality.

Climatic data are examined from an attribution perspective, using fraction of attributable risk (FAR) to quantify anthropogenic GHG influences on record 
SST conditions in the Coral Sea (T1; and second hottest occurrence, T2 in 2004), with multimodel ensemble median and 10th percentile values given (see Lewis and Karoly 2013; 2014). Environmental data are examined from a qualitative perspective, providing information of environmental risk factors that impact reef resilience, and either promoted or inhibited bleaching during 2016. We also compare 2016 conditions with previous severe GBR bleaching events of 1997/98, 2001/02, 2005/06 and 2010/11, although the remotely sensed climatic and environmental datasets used here are of limited length, typically commencing in 2002.

Assessment of climatic factors. We compare the occurrence of threshold-exceeding events for Metrics 1-3 in the variously-forced CMIP5 experiments.

Metric 1. The frequency of JFM SST anomalies in the Coral Sea region exceeding T1 and T2 were compared for greenhouse gas (RCP8.5) and natural-only forced simulations (historicalNat; Fig. 28.1d). There is a significant increase in the likelihood of Metric 1 when anthropogenic forcings are included (Median FAR T1 $=0.85 ; 10$ th percentile FAR T1 $=0.80$ ).

Metric 2. The 2016 observed conditions for combined antecedent and coincident SST anomalies (DJF, together with MAM conditions) do not occur in CMIP5 without anthropogenic forcings (Fig. ES28.2a).

Metric 3. An increase in accumulated heat in the Coral Sea region (as diagnosed by DHW; Fig. 28.1e) is evident in the RCP8.5 experiment, relative to the historicalNat experiment for ${ }^{\circ} \mathrm{C}$-weeks above the 2016 values, including above the bleaching risk threshold of $4^{\circ} \mathrm{C}$-weeks (Liu et al. 2013), although the FAR value is low $\left(\mathrm{T} 4^{\circ} \mathrm{C}\right.$-weeks $\left.=0.24\right)$.

Metric 4. Although Pacific Ocean conditions (Power et al. 1999) influence Australian climatic variability, the relationship between El Niño episodes and positive Coral Sea SST anomalies is weak in observations and CMIP5 simulations both including and excluding anthropogenic influences (Fig. ES28.2). In historicalNat experiments, the likelihood of extreme Coral Sea JFM SST anomalies is increased during El (a)
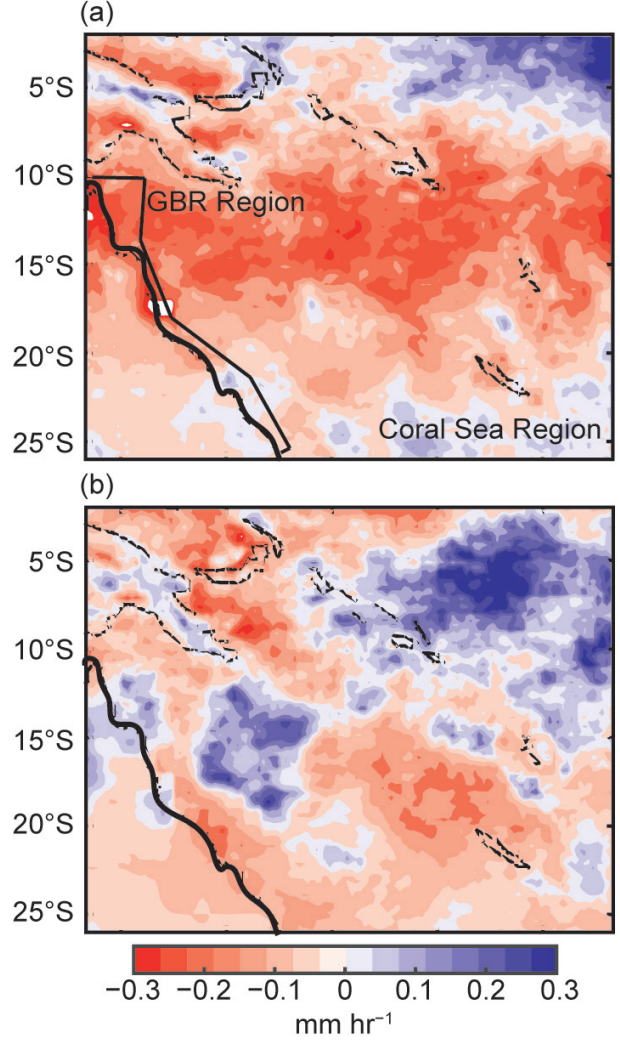

(c)

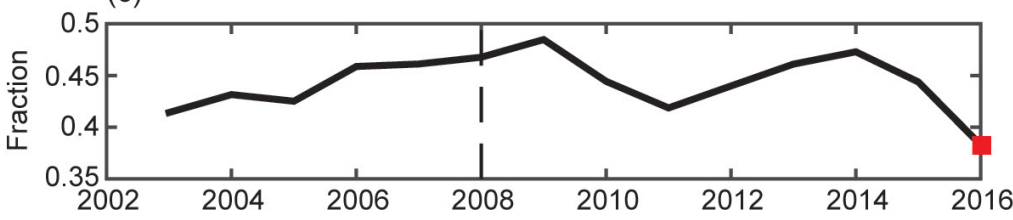

(d)

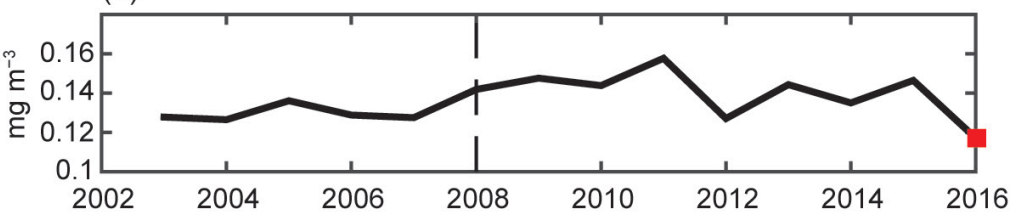

(e)

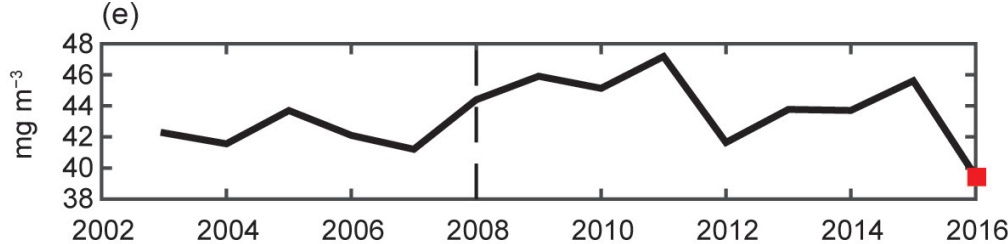

FIG. 28.2. Satellite-derived observational products for JFM precipitation anomalies in the Coral Sea region for (a) 2016 and (b) 1998 ( $\mathrm{mm} \mathrm{hr}^{-1}$; relative to 1998-2016 climatology from TRMM rainfall retrievals for 1998-2016), (c) cloud area fraction (\%; daytime) from AIRS/Aqua retrieval, $I^{\circ} \times 1^{\circ}$ for 2002-I6), (d) chlorophyll-a concentration ( $\mathrm{mg} \mathrm{m}^{-3}$; from MODIS-Aqua 4-km monthly data), and (e) particulate organic carbon ( $\mathrm{mg} \mathrm{m}^{-3}$; from MODIS-Aqua 4-km monthly data). The general location of the GBR is shown in (a). 
Niño phases (Median FAR T1 $=0.94$; 10th percentile FAR T1 $=0.88$, relative to La Niña). The distribution of Coral Sea temperatures during El Niño episodes without greenhouse gases is similar to La Niña events in the RCP8.5 experiment.

Assessment of environmental factors. Potential environmental and local coral stressors were examined qualitatively.

Metric 5 and 6. Lower than average JFM rainfall was observed in the Coral Sea region in 2016 (Fig. 28.2a). Regional rainfall can impact coral through several mechanism; increased land-based rainfall impacts runoff levels and water quality (Graham et al. 2015), while decreased rainfall may be associated with reduced cloud cover and increased temperatures (Nicholls 2003). In 2016, reduced Coral Sea rainfall may have increased the risk of bleaching, in combination with increased temperatures. Reduced cloud cover fraction was also observed in 2016, which can impact bleaching through increasing UV exposure (Fig. 28.2b; Leahy et al. 2013).

Metric 7 and 8. Concentrations of chlorophyll-a and particulate organic carbon (Figs. 28.2b,c) were considered as metrics of local water quality and drivers of bleaching risk during JFM. Corals located at sites with better water quality (reduced particulates and nutrient levels) were less prone to bleaching during previous events (Mallela et al. 2016). In 2016, nutrient loads occurred relative to previous years, which may indicate improved water quality and a lower bleaching risk, compared to the long-term average.

Assessment of bleaching drivers. We examined interrelated climatic and environmental conditions in the Coral Sea that altered the risk of GBR bleaching in 2016 (Table 28.1). Analysis demonstrates that anthropogenic GHG-forced trend in regional SSTs had a dominant impact on bleaching resulting in the record high antecedent and coincident SSTs in 2016 (Metrics 1 and 2), and accumulated heat over this period (Metric 3). A combination of natural climate variability and the 2016 El Niño episode also contributed to ocean conditions resulting in the bleaching (Metrics 4, 5, and 6). Hence, the 2016 extreme thermal stress was due to the added effects of natural variability and ENSO imposed on a regional anthropogenic increase in SSTs.

The Coral Sea ocean conditions resulting in the 2016 GBR bleaching were the result of a confluence of increased risk from anthropogenic GHG-forced trend in regional SSTs, weak El Niño forcing and natural variability (Table 28.1). Differences relative to the 1997/98 massive but less severe bleaching event ( $43 \%$; Hughes et al. 2017), were extremely strong eastern equatorial Pacific El Niño conditions (Figs. ES28.1a,b). The differences in the flavor of El Niño contributed to local SSTs lower in 1998 than 2016 and higher precipitation (Figs. 28.2a,b). Higher local temperatures than 1997/98 were observed in 2001/02 $(\sim 56 \%)$ and 2005/06 when bleaching again occurred (Fig. 28.1a). In contrast, during the 2010/11 bleaching, record high rainfall (Bureau of Meteorology 2012) and runoff contributed to freshwater, rather than thermal stress. While differences in anthropogenic GHG forced trend in regional SSTs were negligible between 2016 and 2015, the additional impacts from the El Niño-Coral Sea SST relationship, combined with other natural climate variability influences, were sufficient to trigger the record 2016 bleaching.

Our study demonstrates that GHG warming of regional sea surface temperatures was the primary increase in risk for the 2016 GBR bleaching. This assessment indicates the risk of future bleaching may become more likely with further greenhouse warming, and that local environmental factors, such as water quality and upwelling will have increasingly limited capacity to remediate anthropogenic drivers of temperature-induced bleaching (Wooldridge 2016b). Furthermore, explorations of drivers of reef bleaching require explicit consideration of biological processes, environmental stressors, ENSO dynamics, anthropogenic warming and their interactions, as bleaching events likely have different drivers.

ACKNOWLEDGMENTS. This research was supported by ARC DECRA grants DE160100092 and DE120101998, and the NCI National Facility. We acknowledge the WCRP's Working Group on Coupled Modelling, which is responsible for CMIP. The U.S. Department of Energy's PCMDI provides CMIP5 coordinating support. 


\section{REFERENCES}

Ainsworth, T. D., S. F. Heron, J. C. Ortiz, P. J. Mumby, A. Grech, D. Ogawa, E. C Mark, and W. Leggat, 2016: Climate change disables coral bleaching protection on the Great Barrier Reef. Proc. Natl. Acad. Sci., 352, 338-342, doi:10.1126/science.aac7125.

Bellwood, D. R., A. S. Hoey, and J. H. Choat, 2003: Limited functional redundancy in high diversity systems: resilience and ecosystem function on coral reefs. Ecol. Lett., 6, 281-285, doi:10.1046/j.1461

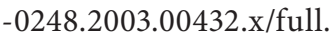

Bureau of Meteorology, 2012: Special Climate Statement 38-Australia's wettest two-year period on record; 2010-2011. [Australia] Bureau of Meteorology, 10 pp. [Available online at www.bom.gov.au/climate /current/statements/scs38.pdf.]

— , 2016: Special Climate Statement 56-Australia's warmest autumn on record. [Australia] Bureau of Meteorology, $21 \mathrm{pp}$. [Available online at www .bom.gov.au/climate/current/statements/scs56.pdf.]

Carilli, J. E., R. D. Norris, B. A. Black, S. M. Walsh, and M. McField, 2009: Local stressors reduce coral resilience to bleaching. PLoS One, 4, e6324, doi:10.1371 /journal.pone.0006324.

Cressey, D., 2016: Coral crisis: Great Barrier Reef bleaching is "the worst we've ever seen." Nature, doi:10.1038 /nature.2016.19747.

Glynn, P. W., and L. D'croz, 1990: Experimental evidence for high temperature stress as the cause of $\mathrm{El}$ Niño-coincident coral mortality. Coral Reefs, 8 , 181-191, doi:10.1007/BF00265009.

Graham, N. A. J., S. Jennings, M. A. MacNeil, D. Mouillot, and S. K. Wilson, 2015: Predicting climate-driven regime shifts versus rebound potential in coral reefs. Nature, 518, 94-97, doi:10.1038/nature14140.

Hughes, T. P., and Coauthors, 2017: Global warming and recurrent mass bleaching of corals. Nature, 543, 373-377, doi:10.1038/nature21707.

Leahy, S. M., M. J. Kingsford, and C. R. Steinberg, 2013: Do clouds save the Great Barrier Reef? Satellite imagery elucidates the cloud-SST relationship at the local scale. PLoS One, 8, e70400-e70412, doi:10.1371 /journal.pone.0070400.

Lewis, S. C., and D. J. Karoly, 2013: Anthropogenic contributions to Australia's record summer temperatures of 2013. Geophys. Res. Lett., 40, 3705-3709, doi:10.1002/grl.50673.
—, and — , 2014: The role of anthropogenic forcing in the record 2013 Australia-wide annual and spring temperatures [in "Explaining Extremes of 2013 from a Climate Perspective"]. Bull. Amer. Meteor. Soc., 95 (9), S31-S34.

Liu, G., A. E. Strong, and W. Skirving, 2003: Remote sensing of sea surface temperatures during 2002 Barrier Reef coral bleaching. Eos, Trans. Amer. Geophys. Union, 84, 137-141, doi:10.1029/2003EO150001.

—, J. L. Rauenzahn, S. F. Heron, C. M. Eakin, W. Skirving, T. R. L. Christensen, A. E. Strong, and J. Li, 2013: NOAA Coral Reef Watch $50 \mathrm{~km}$ satellite sea surface temperature-based decision support system for coral bleaching management. NOAA Tech. Rep. NESDIS 143, 41 pp. [Available online at https:// coralreefwatch.noaa.gov/satellite/publications /NOAA.Tech.Report.143.pdf.]

Mallela, J., S. Hetzinger, and J. Halfar, 2016: Thermal stress markers in Colpophyllia natans provide an archive of site-specific bleaching events. Coral Reefs, 35, 181-186, doi:10.1007/s00338-015-1350-7.

Mann, M. E., S. Rahmstorf, B. A. Steinman, M. Tingley, and S. K. Miller, 2016: The likelihood of recent record warmth. Sci. Rep., 6, 19831, doi:10.1038/srep19831.

Morice, C. P., J. J. Kennedy, N. A. Rayner, and P. D. Jones, 2012: Quantifying uncertainties in global and regional temperature change using an ensemble of observational estimates: The HadCRUT4 data set. J. Geophys. Res., 117, D08101, doi:10.1029/2011JD017187.

Nicholls, N., 2003: Continued anomalous warming in Australia. Geophys. Res. Lett., 30, 1370, doi:10.1029/2003GL017037.

Normile, D., 2016: Survey confirms worst-ever coral bleaching at Great Barrier Reef. ScienceInsider, doi:10.1126/science.aaf9933.

Power, S., T. Casey, C. Folland, A. Colman, and V. Mehta, 1999: Inter-decadal modulation of the impact of ENSO on Australia. Climate Dyn., 15, 319-324, doi:10.1007/s003820050284.

Reynolds, R. W., N. A. Rayner, T. M. Smith, D. C. Stokes, and W. Wang, 2002: An improved in situ and satellite SST analysis for climate. J. Climate, 15, 1609-1625, doi:10.1175/1520-0442(2002)015<1609:AIISAS >2 .0.CO;2.

Taylor, K. E., R. J. Stouffer, and G. A. Meehl, 2012: An overview of CMIP5 and the experiment design. Bull. Amer. Meteor. Soc., 93, 485-498, doi:10.1175/BAMS -D-11-00094.1. 
Weller, E., M. Nunez, G. Meyers, and I. Masiri, 2008: A climatology of ocean-atmosphere heat flux estimates over the Great Barrier Reef and Coral Sea: Implications for recent mass coral bleaching events. J. Climate, 21, 3853-3871, doi:10.1175/2007JCLI2085.1.

Wooldridge, S. A., 2016a: Excess seawater nutrients, enlarged algal symbiont densities and bleaching sensitive reef locations: 1 . Identifying thresholds of concern for the Great Barrier Reef, Australia. Mar. Pollut. Bull., in press, doi:10.1016/j.marpolbul.2016.04.054. , 2016b: Understanding coral bleaching risk factors in the remote far-northern Great Barrier Reef (GBR) that make obvious the best "local" management option for maximising the capacity of the GBR to resist thermal stress and bleaching. CTRMS Research Pub. 01. Catchment to Reef Management Solutions, Newcastle, NSW, Australia, 35 pp. 